Western University

Scholarship@Western

Chemistry Publications

Chemistry Department

$11-10-2009$

\title{
Electrochemical and Photovoltaic Properties of Electropolymerized Poly(thienyl-silole)s
}

Joshua C. Byers

Paul M. DiCarmine

Mahmoud M. A. R. Moustafa

Xin Wang

Brian Pagenkopf

University of Western Ontario, bpagenko@uwo.ca

See next page for additional authors

Follow this and additional works at: https://ir.lib.uwo.ca/chempub

Part of the Chemistry Commons

Citation of this paper:

Byers, Joshua C.; DiCarmine, Paul M.; Moustafa, Mahmoud M. A. R.; Wang, Xin; Pagenkopf, Brian; and Semenikhin, Oleg A., "Electrochemical and Photovoltaic Properties of Electropolymerized Poly(thienyl-silole)s" (2009). Chemistry Publications. 61.

https://ir.lib.uwo.ca/chempub/61 
Authors

Joshua C. Byers, Paul M. DiCarmine, Mahmoud M. A. R. Moustafa, Xin Wang, Brian Pagenkopf, and Oleg A. Semenikhin 


\section{Electrochemical and Photovoltaic Properties of Electropolymerized Poly(thienyl-silole)s}

\begin{tabular}{|r|l|}
\hline Journal: & The Journal of Physical Chemistry \\
\hline Manuscript ID: & jp-2009-04428p.R1 \\
\hline Manuscript Type: & Article \\
\hline Complete List of Authors: & $\begin{array}{l}\text { Byers, Joshua; The University of Western Ontario, Chemistry } \\
\text { DiCarmine, Paul; The University of Western Ontario, Chemistry } \\
\text { Moustafa, Mahmoud; The University of Western Ontario, Chemistry } \\
\text { Wang, Xin; The University of Western Ontario, Department of } \\
\text { Chemistry } \\
\text { Pagenkopf, Brian; The University of Western Ontario, Chemistry } \\
\text { Semenikhin, Oleg; The University of Western Ontario, Department } \\
\text { of Chemistry }\end{array}$ \\
\hline
\end{tabular}

\section{(5)holarONE \\ Manuscript Central}




\title{
Electrochemical and Photovoltaic Properties of
}

\section{Electropolymerized Poly(thienyl-silole)s}

\author{
Joshua C. Byers, Paul M. DiCarmine, Mahmoud M. Abd Rabo Moustafa, Xin Wang, \\ Brian L. Pagenkopf, and Oleg A. Semenikhin*
}

Department of Chemistry, The University of Western Ontario, London, Ontario, N6A 5B7, Canada

\begin{abstract}
AUTHOR EMAIL ADDRESS: osemenik@uwo.ca.
\end{abstract}
RECEIVED DATE (to be automatically inserted after your manuscript is accepted if required according to the journal that you are submitting your paper to)

CORRESPONDING AUTHOR FOOTNOTE *Corresponding author. E-mail: osemenik@uwo.ca.

\begin{abstract}
Electrochemical and photoelectrochemical properties were studied of a series of donor-acceptor materials based on polythiophene modified with silole moieties. The materials were prepared by electrochemical anodic polymerization of 2,5-bis([2,2'-bithiophe]-5-yl)-1,1-dimethyl-3,4-diphenylsilole14 and 2,5-bis([2,2'-terthiophene]-5-yl)-1,1-dimethyl-3,4-diphenyl-silole, as well as copolymerization of these monomers with 2,2'-bithiophene. Photocurrent measurements showed that introduction of silole resulted in a considerable enhancement of the photovoltaic properties of silolecontaining materials and especially the fill factor. However, as demonstrated by Mott-Schottky measurements, electropolymerized silole-containing materials showed a substantial degree of disorder and high density of states in the midgap, which negatively affected their photovoltaic properties. Atomic
\end{abstract}


force microscopy (AFM) and phase imaging revealed the presence of phase segregation and heterogeneity of the silole-containing materials. Interestingly, introduction of siloles suppressed the cathodic (n-type) doping typical for polythiophenes. This work demonstrates that siloles show great promise as electron-acceptor groups for all-organic solar cells; however, further work is required to optimize the properties and performance of poly(thienyl-silole) based materials.

\section{KEYWORDS}

Poly(thienyl-silole)s; Polythiophene; Silole; Electrochemistry; Photoelectrochemistry; Organic SOLAR Cells; Donor-Acceptor Materials.

\section{Introduction}

Organic photovoltaics has become an area of intense research over the past few years due to major environmental concerns and the desire to replace expensive silicon with readily available, inexpensive and easily processable organic materials. The most promising organic solar cells to date are built using the so-called donor-acceptor concept, whereby the efficiency of an organic photoactive material is dramatically increased by adding acceptor units which facilitate the dissociation of photogenerated excitons and decrease the rate of recombination of photoexcited electrons and holes. ${ }^{1,2}$ While the most efficient organic photovoltaic cells to date utilize fullerenes and fullerene derivatives such as PCBM as acceptors, ${ }^{3-7}$ all polymer devices have emerged as attractive alternatives (see e.g. review ${ }^{8}$ by Kroon et. al and references therein). However, polymer solar cells investigated so far typically suffered from poor transport of photoexcited carriers. ${ }^{9,10}$ Specifically, the transport problems manifest themselves through a low fill factor (FF). ${ }^{9}$ What this means is that one typically needs to apply quite high internal electric fields to efficiently separate and collect photoexcited carriers in such cells; as a result, the cells cannot produce high photocurrents at voltages close to the open-circuit voltage $\mathrm{V}_{\mathrm{OC}}$. 
Recently we developed new donor-acceptor materials based on electropolymerized thiophenes modified with silole units in the main chain. ${ }^{11}$ It was shown that introduction of silole, which is an electron acceptor relative to thiophene, ${ }^{12-14}$ resulted in a remarkable increase in the photoefficiency of the polymer material as compared to the non-modified polybithiophene. Importantly, the cells using the silole-containing material also showed a quite high fill factor, in contrast with non-modified polymer based cells.

In this paper we describe in detail our studies of the electrochemical and photoelectrochemical properties of a series of thiophene-silole donor-acceptor materials. Atomic force microscopy (AFM) was used to study the morphology and mechanical properties of the films, as well as the extent of phase segregation and heterogeneity of the silole-containing materials.

\section{Experimental}

\section{$\underline{\text { Equipment and Apparatus }}$}

Three separate 5-ml cells were used for electrochemical polymerization, electrochemical and photoelectrochemical measurements, respectively. The cells were three-electrode Pyrex glass cells without separation of the anodic and cathodic compartments. The working electrode used for polymer deposition and measurement was a $2 \mathrm{~mm}$ platinum disk pressed into a Teflon ${ }^{\mathrm{TM}}$ holder. The counter electrodes were platinum wires. Silver pseudo-reference electrodes were used. They were stored in monomer free solutions containing the corresponding solvent and $0.1 \mathrm{MBu}_{4} \mathrm{NPF}_{6}$. The potential of such electrodes in acetonitrile was found to be $+0.05 \mathrm{~V}$ versus SCE. ${ }^{15}$ All the potentials in this paper are given versus the silver pseudo-reference electrodes. The photoelectrochemical measurements were performed using a $20 \mathrm{~mW}, 405 \mathrm{~nm}$ laser diode model LD1510 (Power Technology, Little Rock, AR). The photon flux used was measured using a calibrated $\mathrm{Si}$ photodiode and was found to be 
$1.8 \times 10^{17} \mathrm{~s}^{-1} \cdot \mathrm{cm}^{-2}$ after correcting for the difference in the diameters of the laser beam and the electrode (3 $\mathrm{mm}$ and $2 \mathrm{~mm}$, respectively). This flux at $405 \mathrm{~nm}$ corresponds to a power of $90 \mathrm{~mW}^{-2}$. No correction for the light absorption by the cell walls and electrolyte was made. In all electrochemical, photoelectrochemical and impedance measurements the electrode was polarized using a model PAR 263A potentiostat-galvanostat (Princeton Applied Research) controlled by a version 2.8 CorrWare electrochemical software (Scribner Associates Inc.). For Mott-Schottky measurements, the potentiostat was coupled to a model 1250 frequency response analyzer (Solartron) controlled by a version 2.8 ZPlot software (Scribner Associates Inc.). AFM measurements were performed using a Multimode AFM (Veeco Metrology) equipped with a Nanoscope IV controller (Veeco). Silicon PointProbe tips (NanoWorld, resonant frequency $320 \mathrm{kHz}$, force constant $42 \mathrm{~N} / \mathrm{m}$ ) were used.

\section{$\underline{\text { Materials }}$}

The precursors for the thiophene-silole donor-acceptor materials used in this study were 2,5-bis([2,2'bithiophe]-5-yl)-1,1-dimethyl-3,4-diphenyl-silole ${ }^{14} \mathbf{3}$ and 2,5-bis([2,2'-terthiophene]-5-yl)-1,1-dimethyl3,4-diphenyl-silole 4 (referred to in the subsequent discussion as Me-TTSTT and Me-TTTSTTT, respectively). One pot, two step methodology involving Tamao's reductive cyclization followed by Negishi cross-coupling was utilized (Scheme 1) to prepare the required silole-thiophene monomers in good overall yield. ${ }^{16,17}$ Mono bromobithiophene and monobromoterthiophene were prepared according to the literature. ${ }^{18-21}$

2,2-Bithiophene (BT) (Aldrich) was purified through vacuum sublimation. The supporting electrolyte for electrochemical measurements was tetrabutylammonium hexafluorophosphate, $\mathrm{Bu}_{4} \mathrm{NPF}_{6}(\mathrm{Sigma}$ Aldrich, $98 \%$ purity, reagent grade), which was stored in a vacuum dessicator over silica gel. Dichloromethane and acetonitrile solvents were purified using an in house solvent purification system. 


\section{$\underline{\text { Polymer film deposition }}$}

The thiophene-silole donor-acceptor materials were prepared by means of electrochemical oxidative polymerization from dichloromethane solutions containing either individual Me-TTSTT or MeTTTSTTT monomer, or a 1:1 mixture of Me-TTSTT or Me-TTTSTTT monomer and BT. The materials prepared by electropolymerization of individual Me-TTSTT or Me-TTTSTTT monomers are further referred to as Me-TTSTT and Me-TTTSTTT polymers, whereas the materials prepared by copolymerization of these silole monomers with BT are referred to as Me-TTSTT-BT and Me-TTTSTTTBT copolymers. The 2:1 ratios of BT to Me-TTSTT and Me-TTTSTTT were also investigated; however, the results presented in this manuscript refer only to copolymers obtained from 1:1 solutions since the 2:1 copolymers produced very similar results. The concentration of each monomer was always $5 \times 10^{-3} \mathrm{M}$. The supporting electrolyte was $0.1 \mathrm{M} \mathrm{Bu}_{4} \mathrm{NPF}_{6}$. The cell was purged with Ar gas prior to electropolymerization and the gas was shut off with the cell sealed during synthesis.

The films were electrochemically polymerized using square wave potentiostatic deposition, as described in our previous communication. ${ }^{11}$ The square wave deposition was used rather than more traditional potentiostatic or galvanostatic regimes because of low reactivity of the silole-containing monomers and the need to rapidly reduce the produced oligomers in the electrode vicinity in order to get at least a fraction of them deposited at the electrode surface. ${ }^{11}$ Specifically, the potential was held at $+1.4 \mathrm{~V}$ for 5 seconds and the potential was rapidly switched and held at a potential of $-0.5 \mathrm{~V}$ for 5 seconds. The number of square wave cycles applied was adjusted to achieve a specific film thickness. The thickness of the films were estimated from the doping-undoping charges using the coefficient $7 \mathrm{~nm}$ $\mathrm{mC}^{-1} \mathrm{~cm}^{-2}$ determined for polybithiophene (PBT) earlier. ${ }^{22}$ We made the assumption that this coefficient holds for the silole-containing films as well. Following deposition the films were reduced at a potential of - $0.2 \mathrm{~V}$ for 100 seconds to convert them to a semiconducting undoped state. The composition of the copolymer films was estimated using the silicon to sulphur ratio measured by XPS (Kratos Axis Ultra), 
which was found to be 1:12 and 1:14 for Me-TTSTT-BT and Me-TTTSTTT-BT copolymers, respectively. These values should be taken only as rough estimates since the intensities of the Si peaks in the XPS spectra were quite low; however, they do indicate a lower reactivity of silole-containing monomers in the electropolymerization reaction. As a result, the silole content in copolymer films was quite small (roughly 1 silole-containing Me-TTSTT or Me-TTTSTTT monomer unit per 4 BT units).

\section{$\underline{\text { Measurement Procedures }}$}

Electrochemical and photoelectrochemical measurements were performed in a $0.1 \mathrm{M}$ solution of $\mathrm{Bu}_{4} \mathrm{NPF}_{6}$ in acetonitrile without the monomer. The electrochemical measurement cell was purged with Ar gas. The gas was shut off and the cell sealed during measurements. Photoelectrochemical measurements were performed in a cell that was continuously bubbled with oxygen gas during measurements. Oxygen functions as an electron acceptor for photoexcited electrons. ${ }^{15}$ The MottSchottky measurements were performed at a constant frequency of $2250 \mathrm{~Hz}$ by scanning the dc potential across the region of interest and measuring the real and imaginary components of the ac current. The amplitude of the ac potential perturbation was $10 \mathrm{mV}$, the potential scan rate was $10 \mathrm{mV} \mathrm{s}^{-1}$.

For AFM measurements the polymer films were electropolymerized onto the surface of highly oriented pyrolytic graphite (HOPG) following as close as possible the procedure for film deposition on platinum. A special three-electrode Teflon $^{\mathrm{TM}}$ cell was used with HOPG as a working electrode, a platinum counter electrode and a silver pseudo-reference electrode. Immediately following the deposition the samples were rinsed with pure solvent and dried under vacuum for 3 days, following the procedure developed earlier. $^{23}$ Tapping mode and phase imaging AFM measurements were then performed in ambient conditions. The phase images provide information about the local mechanical properties and crystallinity of the polymer films. ${ }^{22}$ A more positive phase shift with respect to a free vibrating cantilever is indicative of a harder, more densely packed, typically more crystalline, material. 
Such regions of the polymer show a more positive phase shift and appear as brighter areas in the phase images. More amorphous/less dense polymer domains show pronounced viscoelastic behaviour, which results in a less positive or negative phase shift and so such regions appear as darker areas in the phase images. More details about AFM phase imaging of conducting polymer films can be found elsewhere. ${ }^{22}$

\section{Results and Discussion}

\subsection{Cyclic Voltammetry}

Cyclic voltammetry $(\mathrm{CV})$ is a useful diagnostic tool for determination of the redox properties of polymer electrodes. The onset potentials of the polymer oxidation and reduction processes are loosely related to the positions of the valence and conduction bands for these materials. When copolymers are formed, their CV's can provide insight into the changes in properties for polymer electrodes composed of two different monomers. Cyclic voltammetry was performed in the p-doping and n-doping regions of the silole-containing polymers and copolymers to investigate their redox activity. Separate scans were performed in the anodic and cathodic regions to avoid the appearance of additional peaks associated with the trapped charge. ${ }^{24,25}$ The thickness of each polymer film was approximately $35 \mathrm{~nm}$ and was controlled through the number of square waves applied as described above.

Figures 1 and 2 present anodic cyclic voltammograms obtained for films of Me-TTTSTTT and MeTTSTT polymers and copolymers with BT. Also shown in the figures for the sake of comparison are the anodic curves for the parent PBT polymer. Curves from the second scan are used to avoid the wellknown memory effects. There are a number of features to be noted:

- The cyclic voltammograms for both individual silole-containing polymers and copolymers are typical of conducting polymer electrodes exhibiting broad oxidation and reduction peaks with a pronounced asymmetry. ${ }^{26}$ This type of voltammetric response is associated with the complex 
mechanism of the charging-discharging processes that involves multistep charging of polymer fragments of varying chain lengths, with the asymmetry specifically related to slow structural reorganization of the polymer electrode upon reversal of the scan direction. ${ }^{26}$ Therefore, the silole-containing materials studied in this work are conducting polymers and not redox polymers.

- The doping peaks for all silole-containing materials are broader as compared to PBT. In fact, the anodic peaks for individual Me-TTSTT and Me-TTTSTTT polymers are barely pronounced, thus indicating a greater degree of disorder in silole-containing films. Furthermore, silolecontaining materials show pronounced oxidation currents at higher anodic potentials, which are probably associated with oxidation of short oligomeric fragments.

- The potentials of the doping peaks for silole-containing compounds are slightly less positive as compared to PBT; however, this difference is quite small and does not exceed $0.1 \mathrm{~V}$ for individual Me-TTTSTTT and Me-TTSTT polymers. This effect is even less pronounced in copolymers of both Me-TTTSTTT and Me-TTSTT with BT. Lowering the oxidation potential of a donor-acceptor compound is usually expected due to mixing of the frontier orbitals characteristic of the donor-acceptor effect. The virtual absence of such lowering in silolecontaining compounds may indicate that the position of their HOMO is almost exclusively determined by the polythiophene backbone. This conclusion is supported by the fact that the UV-vis absorption spectra of silole-containing polymers were very similar to those of PBT; ${ }^{11}$ however, it should also be noted that the energies of HOMOs of thiophene and silole moieties are quite close. ${ }^{13}$

- The undoping curves for individual Me-TTSTT and Me-TTTSTTT polymers show no second undoping peak at $0.7-0.8 \mathrm{~V}$ typical to polythiophenes. This fact indicates the differences in the doping mechanisms between silole-containing polymers and regular polythiophenes. The occurrence of the second undoping peak and a considerable difference between the potentials of 
that peak and the doping peak (see for example curve 3 for PBT) are commonly related to aggregation of polymer chains due to strong interchain interactions and formation of extended electronic states delocalized over neighbouring polymer fragments. ${ }^{27}$ Therefore, our voltammetric data suggest the lack or weakness of such interactions in silole-containing polymers.

- Copolymerization of the silole-containing and BT monomers results in a certain blending of their individual redox behaviour.

Cathodic doping of the polymers and copolymers was also studied. Figure 3 illustrates the results obtained for films containing Me-TTTSTTT, while Fig. 4 presents the results for Me-TTSTT polymer and copolymer. Again, for the sake of comparison, voltammograms for PBT cathodic doping-undoping are also shown. For individual Me-TTTSTTT polymer films the onset of reduction occurs earlier and this can be attributed to the presence of the silole group with its low lying LUMO. ${ }^{13,28}$ However, upon reversal of the scan direction the film behaviour suggests an inability to be fully undoped. In other words, cathodic reduction of the individual Me-TTTSTTT polymer is observed; however, it is questionable whether or not this effect can be called cathodic doping since the reversibility of this process is low and the charges associated with the cathodic reduction and especially re-oxidation of the Me-TTTSTTT polymer are lower than those for the parent, PBT. Copolymerization results in a slight improvement in the reversibility of the cathodic doping and the amount of charge associated with it; however, both these parameters are inferior as compared to PBT.

The inability to be cathodically doped is even more pronounced for films based on Me-TTSTT, with the films containing individual Me-TTSTT polymer showing no cathodic doping whatsoever (Fig. 4). Some dopability is retained by films based on Me-TTSTT-BT copolymer; however, the charges and reversibility of cathodic doping for this copolymer are quite low as compared even to individual Me- 
TTTSTTT polymer. Such a drastic ability of the silole moiety to severely hinder or even abolish altogether the cathodic doping of polythiophenes is quite interesting since siloles are known to possess a low lying $\mathrm{LUMO}^{13,20}$ and thus should have an ability to accept electrons more easily. At the same time, such behaviour is known for polythiophenes modified with strong electron-withdrawing groups. A good example is poly(ethylene dioxythiophene) (PEDOT), a very well-known conducting polymer which, however, features very limited n-dopability. ${ }^{29}$

One possible explanation of such behaviour is that silole-containing polymers fail to form extended electronic states, such as bipolarons, upon their reduction. Such behaviour was noted for PEDOT and is considered to be responsible for its low dopability and electronic conductivity in the cathodic potential range. ${ }^{29}$ Electrochemical and chemiluminescence studies of a number of silole-containing molecules ${ }^{14,30}$ suggest that reduction of the silole moiety may result in the formation of highly localized excited species with the negative charge centered on the silole. These excited states are also quite unreactive, as suggested by their long lifetimes. ${ }^{14}$ This fact can very likely prevent the formation of extended electronic states, such as bipolarons or their analogs, optimally encompassing several neighbouring polymer chains, which is an essential requirement of polymer doping. Interestingly, this behaviour correlates with the disappearance of the second reduction peak in the anodic doping process of MeTTSTT polymer, which was associated with formation of extended electronic states delocalized over neighbouring polymer fragments (see above). The extent of electronic localization at the silole moiety in oxidized Me-TTSTT and Me-TTTSTT is less than in their reduced forms; ${ }^{14}$ however, it is still significant as compared to individual polybithiophene and other traditional conducting polymers.

\subsection{Photoelectrochemistry}

Photoelectrochemical measurements in solution are a convenient way to evaluate the photoactivity of novel organic semiconductor materials. Although practical solar cells are likely to use the all solid-state 
architecture, measurements in solution are easier to perform since they eliminate many problems related to engineering of well extracting metal/polymer contacts. If an appropriate electron acceptor is added to the solution, the polymer/solution interface usually shows a good efficiency of extraction of photogenerated carriers, which allows one to separate the factors related to the material performance from those of the cell architecture.

Figure 5 presents typical photocurrent-potential curves for individual Me-TTTSTTT, Me-TTSTT and BT polymers, as well as Me-TTTSTTT-BT and Me-TTSTT-BT copolymers. The presented values are net photocurrents corrected for the dark current. The photocurrents all have negative sign, as was to be expected for p-type semiconductors. One can see that for individual BT, Me-TTSTT and Me-TTTSTTT, the photocurrents are much lower than those for the copolymers. The highest photocurrent obtained is with the Me-TTSTT-BT copolymer, followed by the Me-TTTSTTT-BT copolymer and PBT. Both individual Me-TTSTT and Me-TTTSTTT polymers showed very low photocurrents.

To compare different cells and different materials, it is customary to use the following parameters:

- Open-circuit voltage $\mathrm{V}_{\mathrm{OC}}$, which is the maximum voltage produced by the cell. $\mathrm{V}_{\mathrm{OC}}$ is determined as the potential at which the net photocurrent is equal to zero. It also corresponds to the photovoltage a cell produces without load (the circuit is open).

- Short-circuit current $\mathrm{I}_{\mathrm{SC}}$, which is the maximum current produced by the cell. $\mathrm{I}_{\mathrm{SC}}$ is determined as the photocurrent at which the photovoltage generated by the cell is equal to zero (the circuit is shorted).

- Fill factor FF, which characterizes the shape of the photocurrent-potential curve and the maximum power it can produce. Fill factor is determined using the following equation:

$$
F F=\frac{I_{\max } \cdot V_{\max }}{I_{S C} \cdot V_{O C}}
$$


where $I_{\max }$ and $V_{\max }$ are the photocurrent and voltage at the point where the cell produces the maximum power. For photoelectrochemical cells, the values of $\mathrm{V}_{\mathrm{OC}}$ and $\mathrm{I}_{\mathrm{SC}}$ do not have the same physical meaning since these cells are essentially half-cells and the potentials are measured versus a reference electrode rather than the actual cell back contact. Furthermore, these values are likely to differ from those observed in solid state devices. However, these parameters are still convenient to compare different materials.

To fully characterize and compare the synthesized materials, $\mathrm{V}_{\mathrm{OC}}, \mathrm{I}_{\mathrm{SC}}, \mathrm{I}_{\max }, \mathrm{V}_{\max }$, and FF determined from Fig. 5 are summarized in Table 1. One can see that not only Me-TTSTT-BT and Me-TTTSTTTBT copolymers feature the highest photocurrents; they also show high fill factors as well indicating their potential efficiency in solar cells. The value of the fill factor for PBT is lower indicating low efficiency of charge separation and collection in this material. However, the most surprising result was the poor performance of individual Me-TTSTT and Me-TTTSTTT polymers. In our preliminary communication, ${ }^{11}$ their deficiency was attributed to the extreme thinness of the films of individual silole-containing polymers, which would not allow them to absorb much light. However, in this work we succeeded in preparing thicker electropolymerized films of individual Me-TTSTT and MeTTTSTTT polymers (these films were of the same thickness as the films of individual PBT and copolymers described in Table 1); however, the photocurrents were still extremely low. These results could be explained only with the help of additional experiments such as Mott-Schottky measurements (see below).

Another factor of great importance for solar cells is the stability of the photoeffect. Organic materials are often prone to rapid photodegradation and decay of the photocurrent, which makes them difficult to use in practical solar cells. This is in particular illustrated by Fig. 6 curve 1, which shows the photocurrent magnitude of a PBT photoelectrode rapidly decreasing with time (it should be remembered 
that the photocurrents for all the materials studied here had negative signs). On the contrary, the magnitude of the photocurrents measured with Me-TTSTT-BT and Me-TTTSTTT-BT copolymers was found to actually grow with time reaching a stable plateau, indicating a superior stability of these materials and their great potential for usage in organic solar cells.

\subsection{Mott-Schottky measurements}

The measurements of the interfacial capacitance of conducting polymer films can provide a wealth of information concerning their properties and structure of the polymer/electrolyte solution interface as well as the mechanism of the doping-undoping transformations. In this work, we have been specifically interested in semiconductor properties of our materials, as well as in the flat-band potential $\boldsymbol{E}_{\boldsymbol{f} b}$, which allows one to estimate the work function of a material. These parameters can be determined using socalled Mott-Schottky measurements. In a Mott-Schottky experiment the impedance of a semiconductor film is measured at a fixed frequency as the electrode potential is scanned across a selected potential range. The interfacial capacitance is derived from the imaginary component of the impedance and plotted against the potential.

For a semiconductor under depletion conditions the interfacial capacitance can be reduced to the space charge capacitance $\boldsymbol{C}_{\boldsymbol{S C}}$, which follows the Mott-Schottky equation:

$$
\frac{1}{C_{S C}^{2}}=\left(\frac{2}{e_{0} N_{D} \varepsilon \varepsilon_{0} A^{2}}\right) \cdot\left(E-E_{f b}-\frac{k T}{e_{0}}\right)
$$

where $\boldsymbol{\varepsilon}$ is the dielectric constant of the semiconductor, $\boldsymbol{\varepsilon}_{\mathbf{0}}$ is the permittivity of free space, $\boldsymbol{e}_{\mathbf{0}}$ is the elementary charge, $\boldsymbol{A}$ is the electrode surface area, $\boldsymbol{E}-\boldsymbol{E}_{\boldsymbol{f} b}$ is the potential drop across the space charge region in the semiconductor, $\boldsymbol{k}$ is the Boltzmann constant and $\boldsymbol{T}$ is the absolute temperature. Parameter $\boldsymbol{e}_{0} N_{D}$ represents the density of residual charges within the space charge region. Specifically, for the case 
of a traditional p-type semiconductor, the space charge is set up by negatively charged ionized donor impurities and thus the charge density within the space charge region is denoted as $N_{D}$. In polymer semiconductors, the role of donor impurities is played by residual dopant ions and/or charged defects; however, here we will use the generally accepted notations and denote the concentration of residual charges in the same way, as $N_{D}$.

According to Eq. 2, the dependence of $C_{S C}^{-2}$ vs. $\boldsymbol{E}$ should be a straight line called a Mott-Schottky plot. The flat band potential of the film $\boldsymbol{E}_{f b}$ is given by the intercept of the Mott-Schottky plot with the potential axis. It represents the case where no electric field exists across the semiconductor. For a thinfilm semiconductor, the Mott-Schottky behaviour will be observed only over a certain potential range; at more positive or negative potentials the film will become totally depleted and the interfacial capacitance will be more or less independent of the potential. ${ }^{15}$ The slope of the linear portions of the Mott-Schottky plots allows one to determine the residual charge density $\boldsymbol{e}_{0} \boldsymbol{N}_{\boldsymbol{D}}$.

A representative Mott-Schottky plot for a Me-TTTSTTT-BT copolymer film in solution is shown in Fig. 7. One can see that there is a clear linear portion developed in the potential range between ca. 0.2 and $0.6 \mathrm{~V}$. The capacitance of the film decreases (and $C_{S C}^{-2}$ increases) with the potential becoming more negative, indicating the p-type (anionic) residual doping. This was expected for a polymer prepared by oxidative electropolymerization and is in agreement with the results obtained for other polythiophene polymers. $^{15,31,32}$ At more negative potentials, the film is depleted. All the other polymers and copolymers studied in this work showed similar behaviour.

Table 2 lists the parameters determined from the Mott-Schottky data for films of each material of identical thickness (ca. $35 \mathrm{~nm}$ ). The residual dopant density $\boldsymbol{N}_{\boldsymbol{D}}$ was determined from the slope of the Mott-Schottky plots using Eq. 2, and the flat-band potentials were determined from the intercepts of the 
Mott-Schottky plots with the potential axis. The dielectric constant $\varepsilon$ of the polymer films in their dry state is quite low; however, since our experiments were performed in electrolyte solutions, the films contained considerable amounts of solvent, acetonitrile, which has a higher dielectric constant of $36.6 .^{33}$ Therefore, the value of the dielectric constant of films in solution was taken as determined by the solvent and equal to 36.6. No correction for the surface roughness was made.

From the data of Table 2 one can see that individual Me-TTSTT and Me-TTTSTTT polymers are very different from either Me-TTSTT-BT and Me-TTTSTTT-BT copolymers or pristine PBT: they show much more positive values of $\mathrm{E}_{\mathrm{fb}}$ as well as much higher values of the residual charge densities. On the contrary, all BT-containing copolymers show much less positive values of $\boldsymbol{E}_{f b}$, which are also quite close to each other and to that of PBT. As for the charge densities, they are the lowest in pristine PBT and increase in Me-TTSTT-BT and Me-TTTSTTT-BT copolymers, remaining however well below the values for individual Me-TTSTT and Me-TTTSTTT polymers.

Generally speaking, the lower the residual dopant density, the better semiconductor a polymer is, and one can expect a better photocurrent from it. High dopant concentrations reduce the strength of the electric field that separates photogenerated carriers and guides them to the contacts to be collected; the dopant states in the midgap can also act as efficient recombination centres. Therefore, our MottSchottky data unambiguously suggest that individual Me-TTSTT and Me-TTTSTTT polymers are very poor semiconductors and should show low photoactivity, which is indeed the case (Table 1). Among the rest of the materials, PBT shows the best semiconductor properties, which is to be expected since BT is readily polymerized and the PBT polymer should show the lowest degree of disorder. However, PBT does not have electron acceptor moieties, which results in a low exciton dissociation rate and low photoactivity. Therefore, the highest photoactivity should be expected for Me-TTSTT and MeTTTSTTT copolymers, with the Me-TTSTT copolymer featuring a lower dopant density and being the 
more efficient of the two. Indeed, this is exactly what was shown by the photocurrent measurements (see Table 1).

The origin of the high dopant densities in silole-containing materials is likely to be related to a high degree of disorder. The radical cations of Me-TTSTT and Me-TTTSTT were shown above to be much less reactive as compared to those of BT. As a result, electrochemically polymerized silole-BT copolymers and especially individual Me-TTSTT and Me-TTTSTTT polymers should feature a lower polymerization degree as compared to PBT. Another important factor seems to be the lack of electronic delocalization and the absence of extended bipolaronic states in silole-containing materials (especially, individual Me-TTSTT and Me-TTTSTTT polymers) noted from the electrochemical data. Taken together, these factors result in a high density of defects and in a considerable extent of trapping of the residual charge due to poor interchain transport in silole-containing films, which are indeed observed as high values of the residual dopant densities in these materials as indicated by the Mott-Schottky data (Table 2). The high degree of disorder and the lack of efficient interchain transport should also reduce the mobilities of photoexcited carriers, which greatly impedes their collection at contacts and thus reduces the values of the photocurrent generated. These factors should be extremely severe for individual Me-TTSTT and Me-TTTSTTT polymers and somewhat mitigated by the presence of PBT fragments in Me-TTSTT-BT and Me-TTTSTTT-BT copolymers. The BT monomer is readily polymerized and should improve the charge transport and reduce the charge trapping in the copolymers, which is indeed observed in both electrochemical and Mott-Schottky experiments.

The values of $\boldsymbol{E}_{f b}$ provide information about the position of the Fermi level of a semiconductor and thus about its work function. At a first glance, it would seem that the position of the Fermi level for individual Me-TTSTT and Me-TTTSTTT polymers is ca. $0.3 \mathrm{~V}$ lower as compared to PBT and copolymers. However, this would contradict the conclusion reached earlier on the basis of voltammetric 
data that the introduction of the silole moiety does not significantly affect the orbital energies (or band edge positions) of the polymers (at least, for their HOMOs). However, the $\boldsymbol{E}_{f b}$ values determined from Mott-Schottky plots may be affected by a phenomenon known as Fermi level pinning.

In brief, if there is a large density of states in the midgap or at the surface, they may "pin" the Fermi level of the semiconductor and stop the Fermi level from going down to attain the flat-band conditions. Therefore, the flat-band conditions will be reached at more positive potentials as compared to the case without the Fermi level pinning. Large densities of states can result in large shifts in the apparent position of $\boldsymbol{E}_{f b}$, up to $1 \mathrm{~V}$. Therefore, it is possible that the observed shift in the position of $\boldsymbol{E}_{f b}$ is related to the pronounced Fermi level pinning in silole-containing materials. This is well supported by the trend in the values of residual dopant densities. Individual Me-TTSTT and Me-TTTSTTT polymers show very high values of the residual dopant concentration (Table 2) indicating that there is a high density of dopant states in the midgap. It is entirely possible that these states will simultaneously pin the Fermi level causing the observed shift in its apparent position towards more positive values.

\subsection{AFM imaging}

Atomic force microscopy (AFM) was used to investigate the nanoscale properties of the polymer electrodes and relate the observed topographical and morphological features to the photoelectrochemical properties of the films. Figure 8a-d shows representative images of topography (left image of each pair) and phase (right image) of thin films of the four polymers and copolymers under study. The topographic images indicate that films prepared with Me-TTTSTTT appear to be more compact as a result of its increased reactivity compared to films containing Me-TTSTT. The morphology of Me-TTTSTTT copolymers is quite similar to PBT polymer films. ${ }^{22}$ Phase images for the polymer films demonstrate a well-pronounced correlation with the topography, in line with the data obtained in our group earlier for 
$\mathrm{PBT}^{22}$ Each individual polymer grain comprises both crystalline and amorphous regions, with single or multiple crystalline regions surrounded by more amorphous regions located at the grain periphery. This behavior is due to preferential deposition of more crystalline polymer at the early nucleation stages and was examined in detail elsewhere ${ }^{22}$ for non-modified polybithiophene. To illustrate this further, Fig. 8e shows representative images of topography and phase of a thin film of electropolymerized individual Me-TTSTT polymer at a very early stage of its electropolymerization. The images show that the primary polymer nuclei are almost $100 \%$ crystalline, in line with our earlier findings for non-modified PBT. $^{22}$ However, as the primary nuclei grow, the degree of crystallinity and the distribution of the crystalline and amorphous regions begin to vary significantly for individual Me-TTSTT and MeTTTSTTT polymers and Me-TTSTT-BT and Me-TTTSTTT-BT copolymers.

\section{Specifically, the phase images for the individual Me-TTSTT polymer and Me-TTSTT-BT copolymer} show signs of phase segregation. There are well defined areas of increased density / crystallinity in the centres of the grains, with areas of more amorphous material found around these regions. The size of these well-defined dense /crystalline domains is ca. $10-30 \mathrm{~nm}$. These areas are in turn surrounded by more dense material found at the grain periphery, in contrast to the pattern observed for the parent nonmodified polymer, polybithiophene, which featured crystalline grains with no dense/crystalline material at the grain periphery. ${ }^{22}$ The images for Me-TTTSTTT-based materials show smaller grains which have some crystalline domains surrounded by more amorphous regions. Now the degree of crystallinity is noticeably lower and there are no clear-cut boundaries between the amorphous and crystalline domains in these materials, especially, in Me-TTTSTTT-BT copolymer, similarly to the behaviour observed with regular PBT (see ref. 22).

Individual Me-TTSTT polymer films could be expected to feature the smallest degree of polymerization due to low reactivity of Me-TTSTT radical cations as compared to Me-TTTSTTT and 
PBT. It could be argued that short chains of this polymer can more easily align together to form crystalline domains, which are evident in the phase images for the individual Me-TTSTT polymer (Figs. 8a,e). When Me-TTSTT is copolymerized with BT, two possible scenarios can be realized. In the first scenario, electrogenerated Me-TTSTT radical-cations or dications reacts with BT ones creating long chains of polymer incorporating both BT and Me-TTSTT units. In the other scenario, the reactivities of Me-TTSTT and BT are too different and the majority of BT monomer molecules react with each other to form the polybithiophene matrix, while Me-TTSTT molecules react to a much lesser extent and form silole-rich aggregates embedded in the polybithiophene matrix. The phase images of Fig. 8 seem to indicate the second scenario for the Me-TTSTT-based materials, which may be responsible for the peculiar distribution of the crystalline and amorphous phases in these materials with two areas of increased density/crystallinity located one at the grain cores and the other at the grain periphery (Figs. 8a,b). At the same time, phase images for the Me-TTTSTTT materials (Figs. 8c,d) and especially for the Me-TTTSTTT-BT copolymer much more resemble non-modified PBT, which may indicate that the phase segregation and formation of silole-rich domains are less or not pronounced in these materials. A possible reason for this is that Me-TTTSTTT should be much closer in its reactivity and properties to bithiophene due to the increased number of thiophene rings flanking the silole moiety.

The phase segregation could be advantageous for the photovoltaic effect since it may facilitate the dissociation of primary excitons as well as collection of electrons and holes formed in this process. The excitons can be efficiently dissociated at the well defined boundaries between the silole-rich acceptor aggregates and silole-depleted donor domains. From this viewpoint, the most efficient materials should be both the individual Me-TTSTT polymer and Me-TTSTT-BT copolymer. However, the photoefficiency also depends on other factors, such as the residual dopant density indicated by the MottSchottky measurements and the efficiency of charge transport in the polymer material. Therefore, the overall photoefficiency of individual Me-TTSTT and Me-TTTSTT polymers is low due to a very high 
concentration of residual dopant charge trapped within these domains. Copolymerization with BT results in enhanced charge transport, lower degree of charge trapping, and therefore enhanced photoactivity, with the highest photocurrents obtained with Me-TTSTT-BT copolymer, which also features the most pronounced phase segregation. However, additional evidence may be needed to prove that the observed difference is indeed due to this effect. An alternative explanation may be the distinctly bigger grain size observed for Me-TTSTT-BT copolymer films, as compared to Me-TTTSTTT-BT copolymer (see Figs. 8 b and d). Bigger grain sizes mean that a carrier needs to cross a smaller number of grain boundaries in order to be collected. The grain boundaries are typically considered main contributors to the low mobility/conductivity of organic materials. However, the variations in the photoactivity between the Me-TTSTT-BT and Me-TTTSTTT-BT copolymers remain less significant as compared to the difference between the photocurrents observed for individual silole-containing polymers and copolymers, as well as between the silole-based materials and non-modified PBT. Specifically, it was found that the highest photocurrents were observed with materials performed by copolymerization of silole-containing monomers and 2,2'-bithiophene, and that this photocurrent enhancement should be related to the electron-acceptor properties of the silole moiety.

\section{Conclusions}

In summary, the photoactivity of silole-containing materials studied in this work was found to depend on the composition as well as electronic and structural factors. Among these factors are the nature and reactivity of the silole-containing monomer units and whether they were individually polymerized or copolymerized with bithiophene. Individual Me-TTSTT and Me-TTTSTT polymers featured largely localized electronic states and a considerable extent of charge trapping, which resulted in poor semiconductor properties and therefore poor photoactivity. Copolymerization with BT resulted in enhanced charge transport, less pronounced charge trapping, and therefore enhanced photoactivity. An 
additional positive factor seems to be nanoscale phase segregation revealed by phase-imaging AFM in Me-TTSTT-BT copolymer, which was also found to feature the highest photoactivity among the materials studied in this work. However, this material is far from being well optimized, as shown for instance by comparison of its semiconductor properties to those of pristine polybithiophene.

Therefore, while poly(thienyl-silole)s are promising materials for solar cell application, as indicated by well pronounced donor-acceptor effect and high fill factors, much work needs to be done to optimize the distribution of silole and thiophene moieties to engineer both efficient donor-acceptor effect and efficient transport and collection of photogenerated carriers. An ideal material would combine a high polymerization degree, controlled structure and optimized donor-acceptor effect with facile charge transport and low charge trapping. To make such a material, one will need to exercise precise control over the composition and morphology of the prepared materials, which is quite difficult to achieve using electropolymerization and especially co-polymerization. At the same time, individual silole polymers are unlikely to be highly photoactive because of charge localization inherent to these materials. Further investigations will be focusing on strategies to blend the thienyl-silole moieties with efficient electron/hole transport materials to improve the charge collection efficiency while preserving and improving the donor-acceptor effect.

ACKNOWLEDGMENT: The support of this work by the Natural Sciences and Engineering Research Council of Canada (NSERC), Canada Foundation for Innovation/Ontario Innovation Trust (CFI/OIT), The Egyptian academy of scientific research and technology and the Academic Development Fund of the University of Western Ontario is gratefully acknowledged. The authors are grateful to Surface Science Western and personally to Mr. M. Biesinger for help with XPS measurements. 


\section{References and Notes}

1. Tang, C. W. Appl. Phys. Lett. 1986, 48, 183-185.

2. Yu, G.; Gao, J.; Hummelen, J. C.; Wudl, F.; Heeger, A. J. Science 1995, 270, 1789-1791.

3. Hoppe, H.; Sariciftci, N. S. J. Mater. Chem. 2006, 16, 45-61.

4. Kim, Y.; Cook, S.; Tuladhar, S. M.; Choulis, S. A.; Nelson, J.; Durrant, J. R.; Bradley, D. D. C.; Giles, M.; Mcculloch, I.; Ha, C. S.; Ree, M. Nat. Mater. 2006, 5, 197-203.

5. Peet, J.; Kim, J. Y.; Coates, N. E.; Ma, W. L.; Moses, D.; Heeger, A. J.; Bazan, G. C. Nat. Mater. 2007, 6, 497-500.

6. Gunes, S.; Neugebauer, H.; Sariciftci, N. S. Chem. Rev. 2007, 107, 1324-1338.

7. Blouin, N.; Michaud, A.; Gendron, D.; Wakim, S.; Blair, E.; Neagu-Plesu, R.; Belletete, M.; Durocher, G.; Tao, Y.; Leclerc, M. J. Am. Chem. Soc. 2008, 130, 732-742.

8. Kroon, R.; Lenes, M.; Hummelen, J. C.; Blom, P. W. M.; De Boer, B. Polym. Rev. 2008, 48, $531-582$.

9. Mandoc, M. M.; Veurman, W.; Koster, L. J. A.; De Boer, B.; Blom, P. W. M. Adv. Funct. Mater. 2007, 17, 2167-2173.

10. DiCarmine, P. M.; Semenikhin, O. A. Electrochim. Acta. 2008, 53, 3744-3754.

11. DiCarmine, P. M.; Wang, X.; Pagenkopf, B. L.; Semenikhin, O. A. Electrochem. Commun. 2008, 10, 229-232.

12. Tamao, K.; Uchida, M.; Izumizawa, T.; Furukawa, K.; Yamaguchi, S. J. Am. Chem. Soc. 1996, 
$118,11974-11975$.

13. Yamaguchi, S.; Tamao, K. J. Chem. Soc. Dalton. 1998, 3693-3702.

14. Booker, C.; Wang, X.; Haroun, S.; Zhou, J. G.; Jennings, M.; Pagenkopf, B. L.; Ding, Z. F. Angew. Chem. Int. Edit. 2008, 47, 7731-7735.

15. Semenikhin, O. A.; Hossain, M. M. D.; Workentin, M. S. J. Phys. Chem. B 2006, 110, 2018920196.

16. Yamaguchi, S.; Goto, T.; Tamao, K. Angew. Chem. Int. Edit. 2000, 39, 1695-+.

17. King, A. O.; Okukado, N.; Negishi, E. I. Chem. Commun. 1977, 683-684.

18. Albers, W. M.; Canters, G. W.; Reedijk, J. Tetrahedron 1995, 51, 3895-3904.

19. Frigoli, M.; Moustrou, C.; Samat, A.; Guglielmetti, R. Helv. Chim. Acta. 2000, 83, 3043-3052.

20. Roncali, J.; Giffard, M.; Frere, P.; Jubault, M.; Gorgues, A. Chem. Commun. 1993, 689-691.

21. Didier, D.; Sergeyev, S.; Geerts, Y. H. Tetrahedron 2007, 63, 941-946.

22. O'Neil, K. D.; Semenikhin, O. A. J. Phys. Chem. C 2007, 111, 14823-14832.

23. O'Neil, K. D.; Shaw, B.; Semenikhin, O. A. J. Phys. Chem. B 2007, 111, 9253-9269.

24. Semenikhin, O. A.; Ovsyannikova, E. V.; Ehrenburg, M. R.; Alpatova, N. M.; Kazarinov, V. E. J. Electroanal. Chem. 2000, 494, 1-11.

25. Zotti, G.; Schiavon, G.; Zecchin, S. Synth. Met. 1995, 72, 275-281.

26. Audebert, P; Miomandre, F. Electrochemistry of Conducting Polymers. Handbook of Conducting Polymers, $3^{\text {rd }}$ edition; Skotheim, T.A., Reynolds, J.R., Eds.; CRC Press/Taylor and 
Francis: Boca Raton, FL, 2007; Volume 1, 18-1-18-40.

27. Vorotyntsev, M. A.; Heinze, J. Electrochim. Acta. 2001, 46, 3309-3324.

28. Yamaguchi, S.; Tamao, K. Chem. Lett. 2005, 34, 2-7.

29. Ahonen, H. J.; Lukkari, J.; Kankare, J. Macromolecules 2000, 33, 6787-6793.

30. Sartin, M. M.; Boydston, A. J.; Pagenkopf, B. L.; Bard, A. J. J. Am. Chem. Soc. 2006, 128, 10163-10170.

31. Tindale, J. J.; Holm, H.; Workentin, M. S.; Semenikhin, O. A. J. Electroanal. Chem. 2008, 612, 219-230.

32. Semenikhin, O. A.; Ovsyannikova, E. V.; Alpatova, N. M.; Rotenberg, Z. A. J. Electroanal. Chem. 1996, 408, 67-75.

33. CRC Handbook of Chemistry and Physics, $89^{\text {th }}$ Edition; Lide, D.R., Ed.; CRC Press/Taylor and Francis: Boca Raton, FL, 2009.

\section{FIGURE CAPTIONS}

Scheme 1. Synthesis of silole-thiophene monomers.

Figure 1. Anodic cyclic voltammograms for electropolymerized (1) Me-TTTSTTT, (2) Me-TTTSTTTBT and (3) BT films on platinum. Scan rate $100 \mathrm{mV} / \mathrm{s}$.

Figure 2. Anodic cyclic voltammograms for electropolymerized (1) Me-TTSTT, (2) Me-TTSTT-BT and (3) BT films on platinum. Scan rate $100 \mathrm{mV} / \mathrm{s}$.

Figure 3. Cathodic cyclic voltammograms for electropolymerized (1) Me-TTTSTTT, (2) MeTTTSTTT-BT and (3) BT films on platinum. Scan rate $100 \mathrm{mV} / \mathrm{s}$. 
Figure 4. Cathodic cyclic voltammograms for electropolymerized (1) Me-TTSTT, (2) Me-TTSTT-BT and (3) BT films on platinum. Scan rate $100 \mathrm{mV} / \mathrm{s}$.

Figure 5. Photocurrent-potential curves obtained in solution for (1) Me-TTTSTTT, (2) Me-TTSTT, (3) BT, (4) Me-TTTSTTT-BT, (5) Me-TTSTT-BT polymers.

Figure 6. Photocurrent transients obtained in solution for (1) BT and (2) Me-TTSTT-BT polymers.

Figure 7. A representative Mott-Schottky plot obtained in solution for a Me-TTTSTTT-BT copolymer film.

Figure $8.500 \mathrm{~nm}$ x $500 \mathrm{~nm}$ AFM images of topography (left) and phase (right) for electropolymerized films of (a,e) Me-TTSTT; (b) Me-TTSTT-BT; (c) Me-TTTSTTT; (d) Me-TTTSTTT-BT. The color

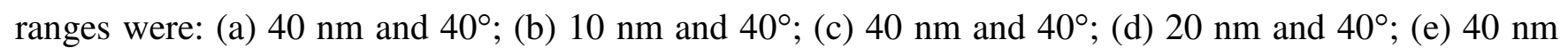
and $40^{\circ}$. The films (a-d) were prepared using 60 square waves, while film (e) was made using 5 square waves to show the early stages of the polymer deposition. Note the clearly pronounced HOPG step in the image. 


\section{TABLES.}

Table 1. Parameters derived from photocurrent-potential curves.

\begin{tabular}{|l|c|c|c|c|c|}
\hline Polymer & $\mathbf{V}_{\text {oc }} / \mathbf{V}$ & $\mathbf{I}_{\mathbf{s c}} / \mathbf{u A ~} \mathbf{~ c m}^{-2}$ & $\mathbf{I}_{\mathbf{m a x}} / \mathbf{u A} \mathbf{c m}^{-2}$ & $\mathbf{V}_{\mathbf{m a x}} / \mathbf{V}$ & $\mathbf{F F} / \%$ \\
\hline PBT & 0.48 & 29 & 19 & 0.30 & 40 \\
\hline Poly(TTSTT) & 0.47 & 12 & 4.7 & 0.42 & 35 \\
\hline Poly(TTTSTTT) & 0.5 & 10 & 3.2 & 0.28 & 18 \\
\hline $\begin{array}{l}\text { Poly(TTSTT- } \\
\text { BT) }\end{array}$ & 0.47 & 137 & 96 & 0.325 & 51 \\
\hline $\begin{array}{l}\text { Poly(TTTSTTT- } \\
\text { BT) }\end{array}$ & 0.47 & 70 & 62 & 0.32 & 60 \\
\hline
\end{tabular}

Table 2. Parameters derived from Mott-Schottky measurements.

\begin{tabular}{|l|c|c|c|}
\hline Polymer & $\mathbf{E}_{\mathbf{f b}} / \mathbf{V}$ & $\mathbf{N}_{\mathbf{D}} / \mathbf{c m}^{-3}$ & $\mathbf{E}_{\mathbf{d e p l e t i o n}} / \mathbf{V}$ \\
\hline PBT & 0.48 & $3.1 \times 10^{17}$ & 0.23 \\
\hline Poly(TTSTT) & 0.83 & $1.1 \times 10^{20}$ & 0.66 \\
\hline Poly(TTTSTTT) & 0.8 & $1.0 \times 10^{20}$ & 0.56 \\
\hline $\begin{array}{l}\text { Poly(TTSTT- } \\
\text { BT) }\end{array}$ & 0.51 & $2.6 \times 10^{18}$ & 0.21 \\
\hline $\begin{array}{l}\text { Poly(TTTSTTT- } \\
\text { BT) }\end{array}$ & 0.54 & $1.2 \times 10^{19}$ & 0.17 \\
\hline
\end{tabular}




\section{FIGURES}

Scheme 1.

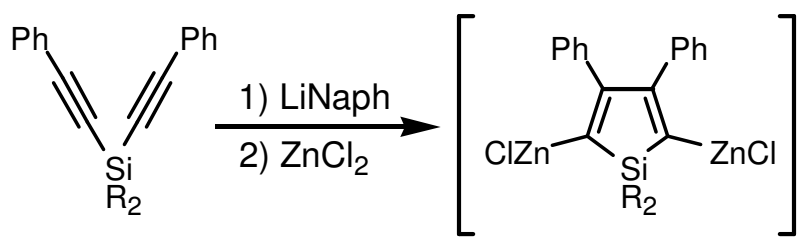

1

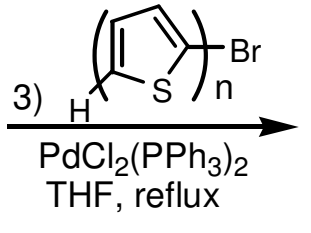

2<smiles>Cc1ccc(-c2[se]c(-c3ccc(C)s3)c(-c3ccccc3)c2-c2ccccc2)s1</smiles>

3, $n=2,83 \%$ from 1 $4, n=2,90 \%$ from 1

Figure 1.

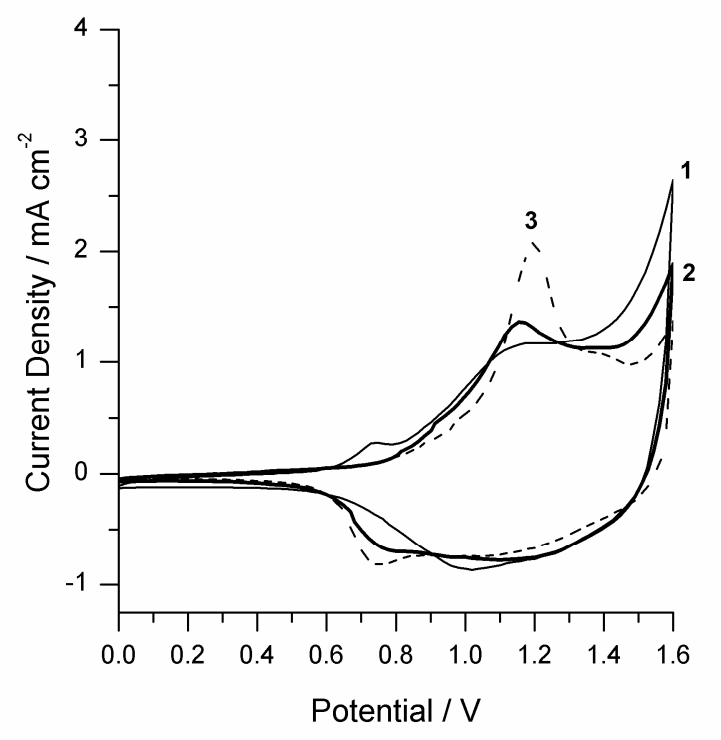


Figure 2.

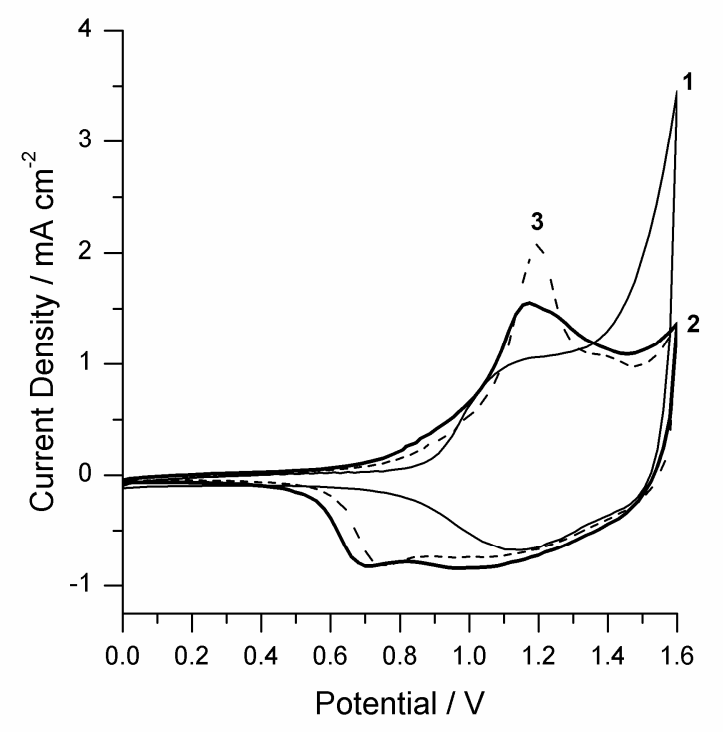

Figure 3.

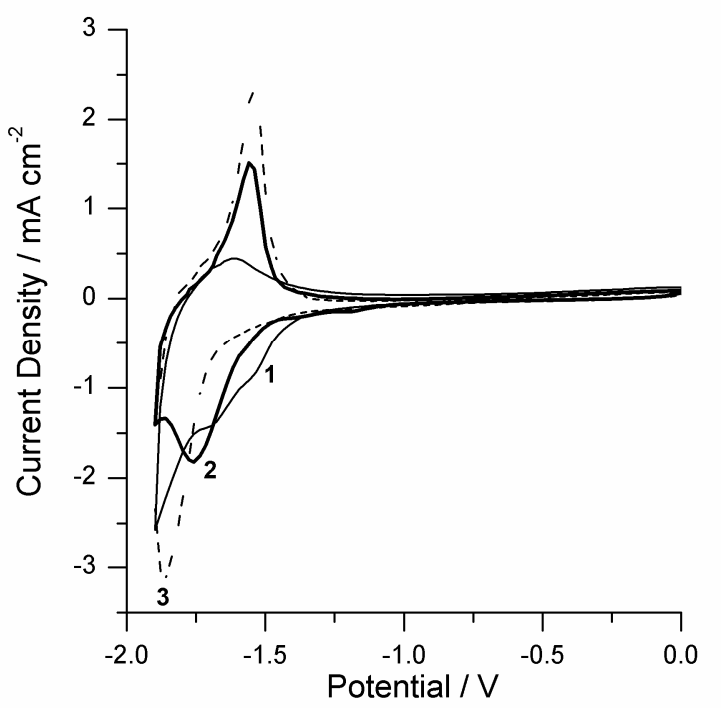

44

45

46

47

48

49

50

51

52

53

54

55

56

57

58

59

60 
Figure 4.

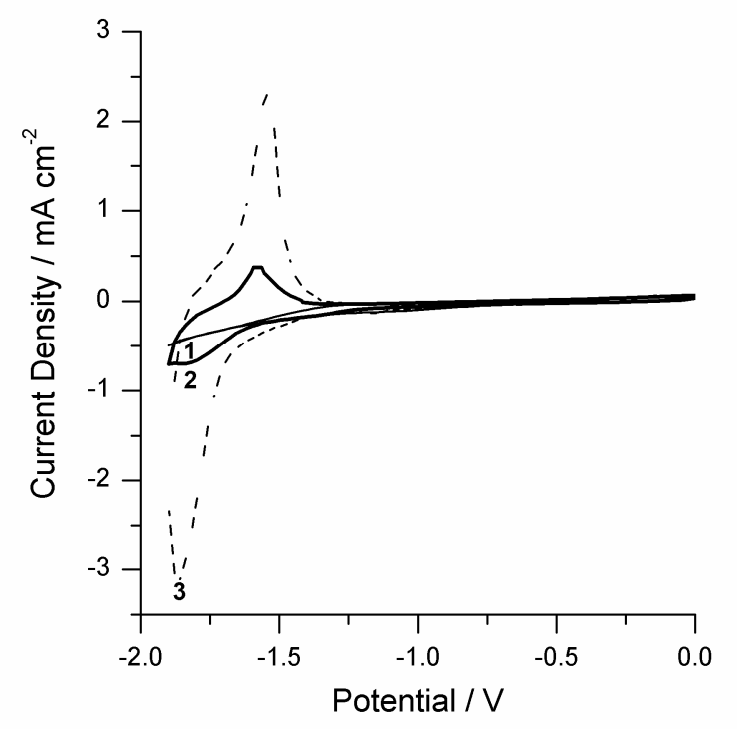

Figure 5.

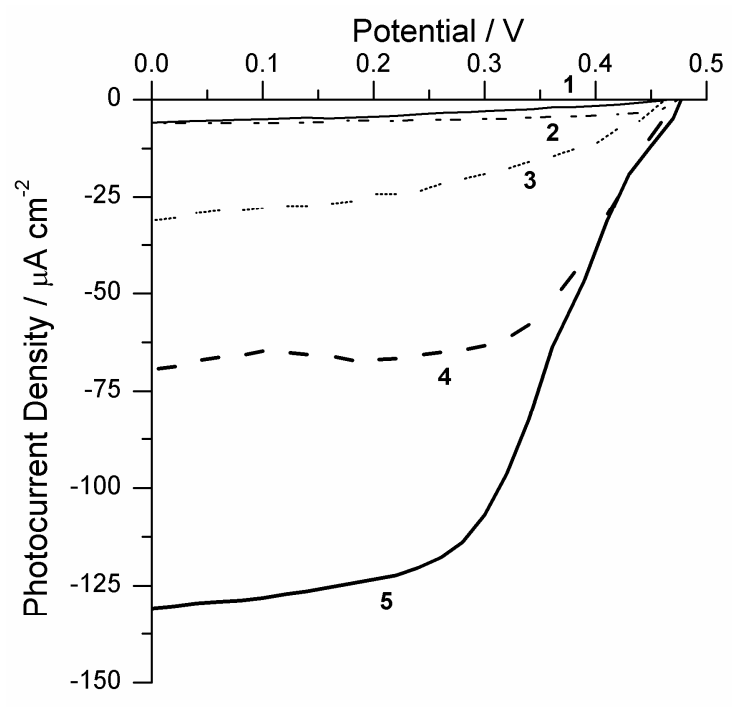


Figure 6.

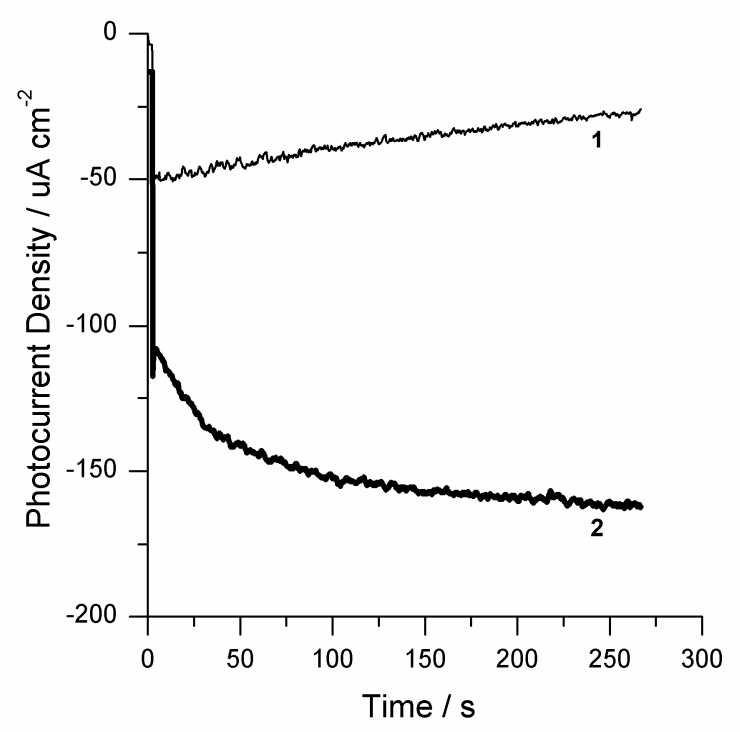

Figure 7.

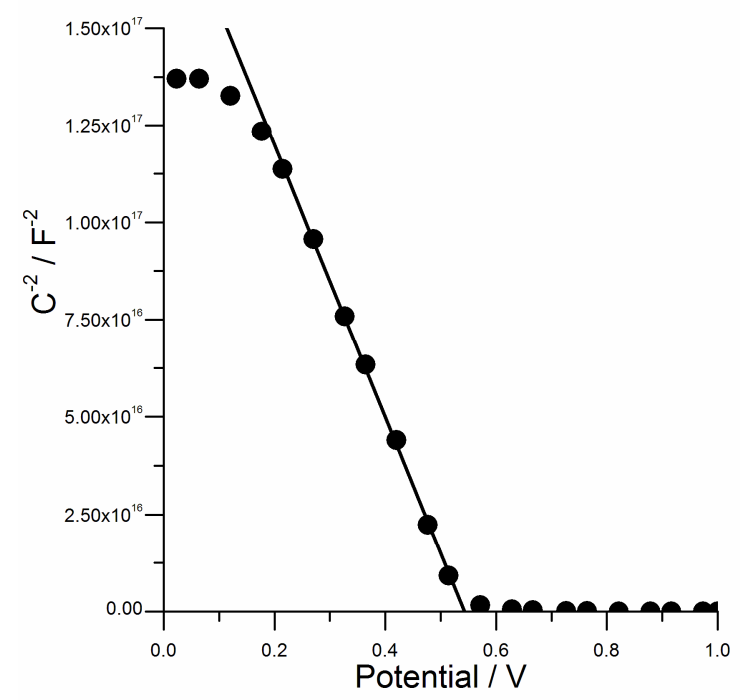

44

45

46

47

48

49

50

51

52

53

54

55

56

57

58

59

60 
Figure 8a.

1
2
3
4
5
6
7
8
9
10
11
12
13
14
15
16
17
18
19
20
21
22
23
24
25
26
27
28
29
30
31
32
33
34
35
36
37
38
39
40
41
42
43
44
45
46
47
48
49
50
51
52
53
54
55
56
57
58
59
60

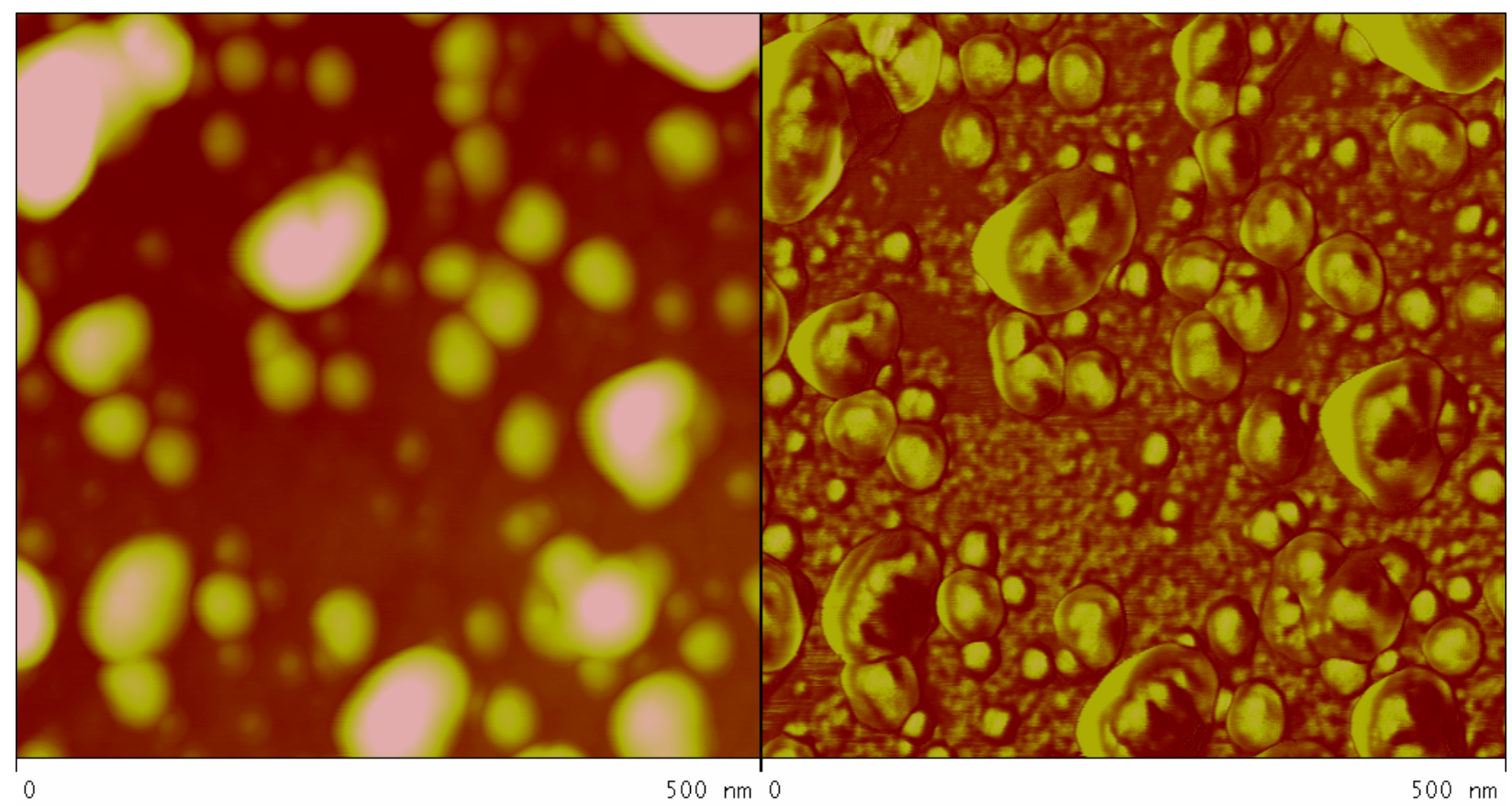

Figure $8 b$.

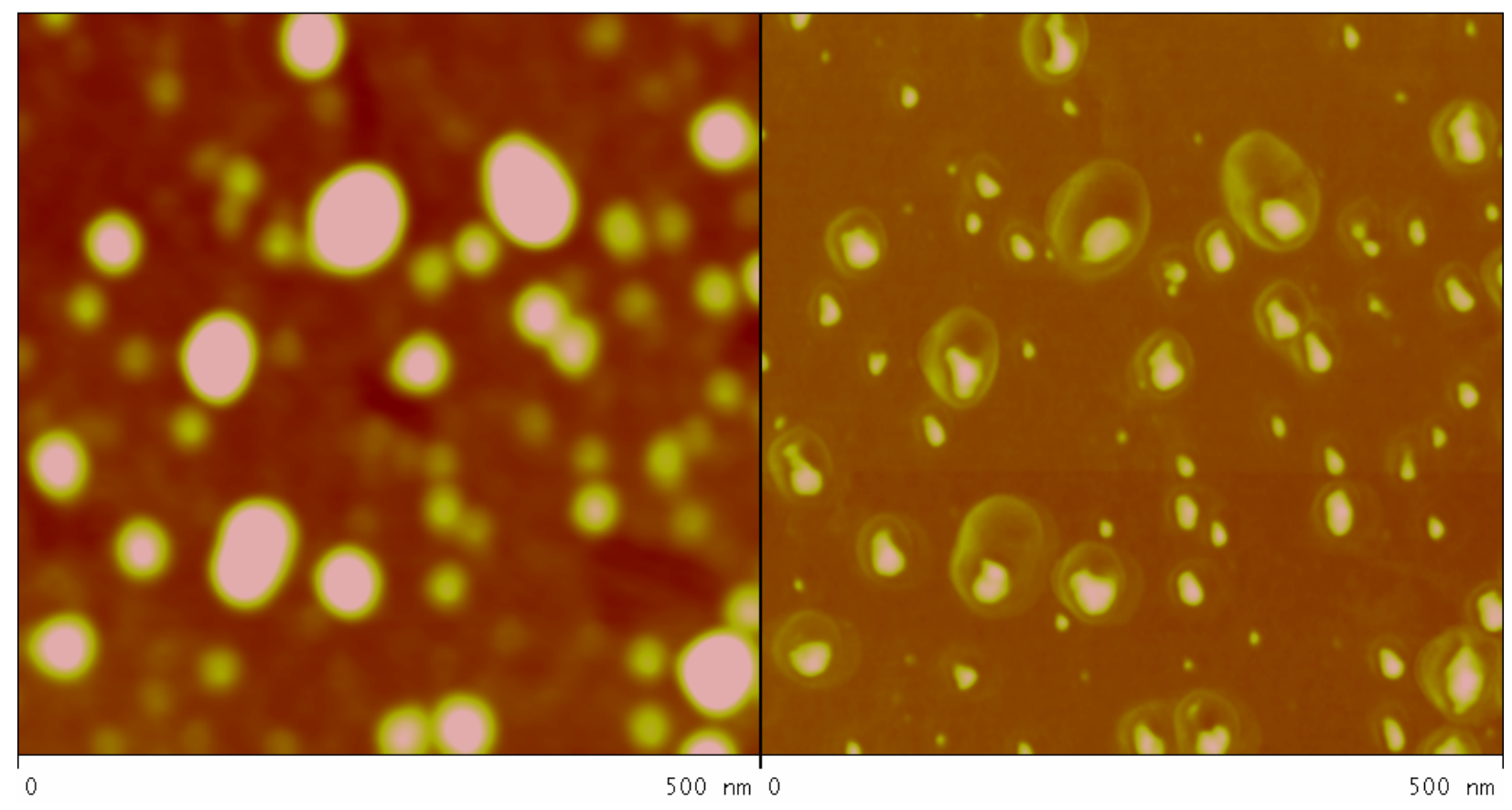


Figure 8c.

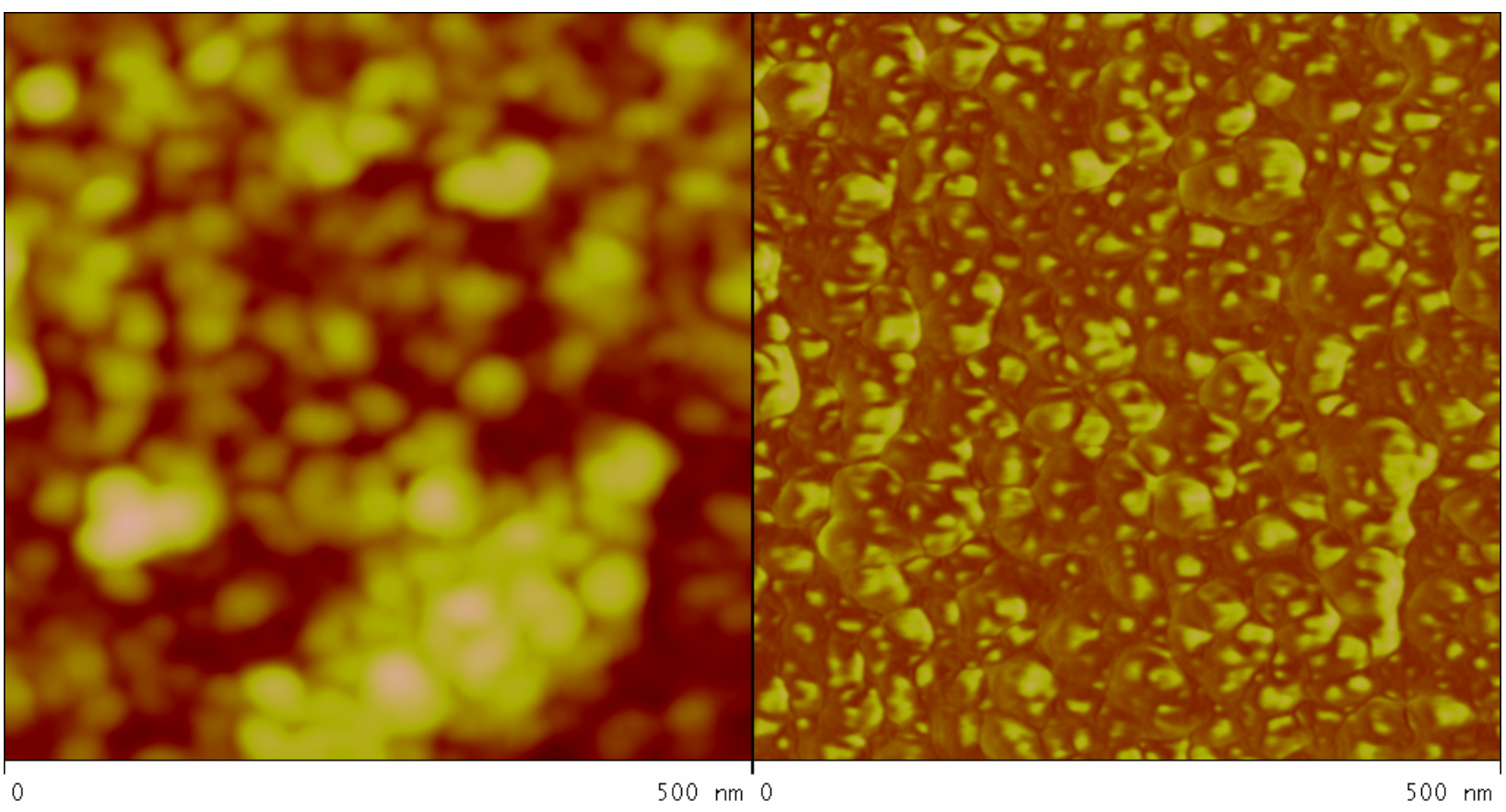

Figure 8d.

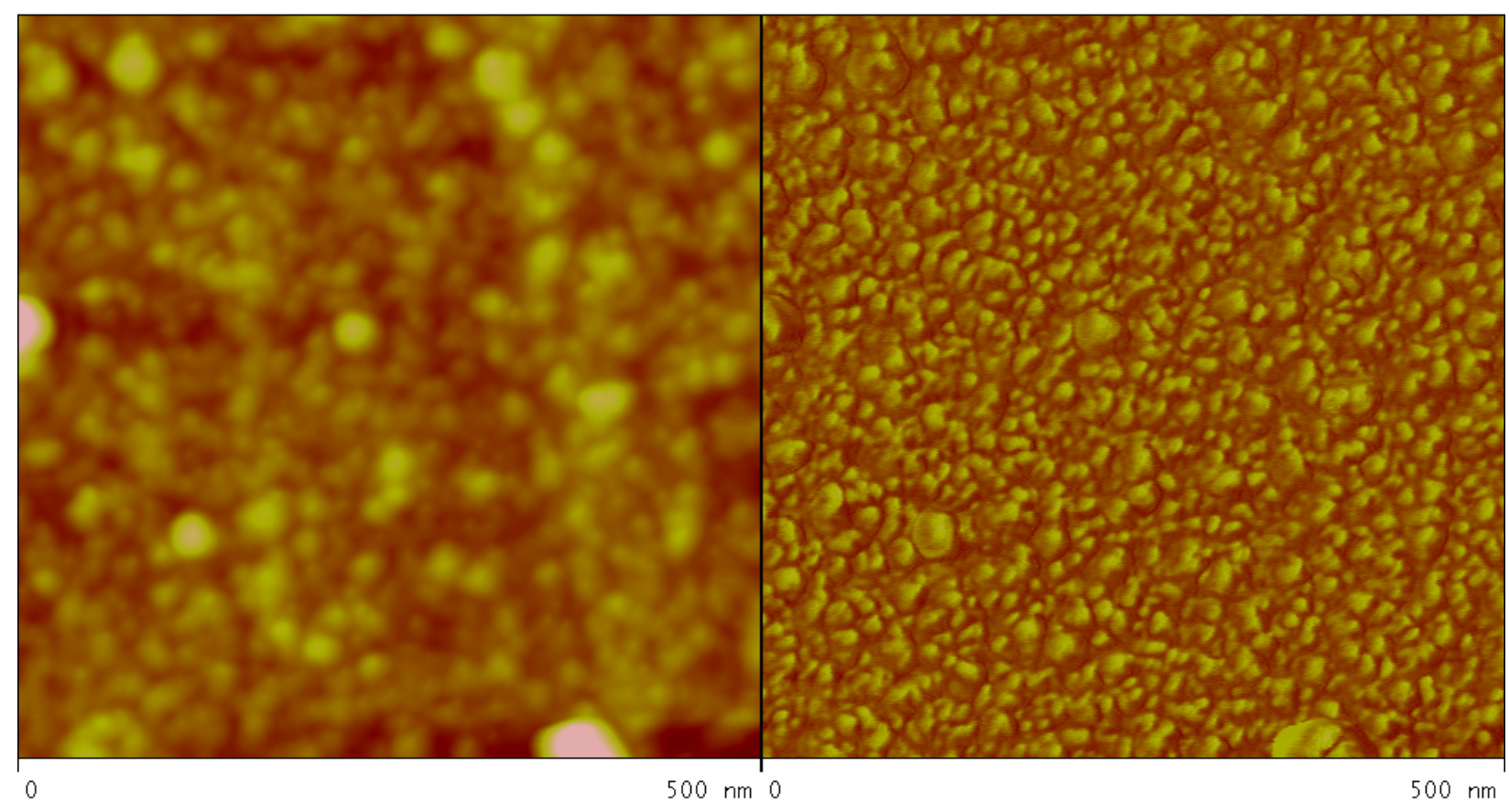


Figure 8e.

2
3
4
5
6
7
8
9
10
11
12
13
14
15
16
17
18
19
20
21
22
23
24
25
26
27
28
29
30
31
32
33
34
35
36
37
38
39
40
41
42
43
44
45
50
59
59
58
49
50
51
50

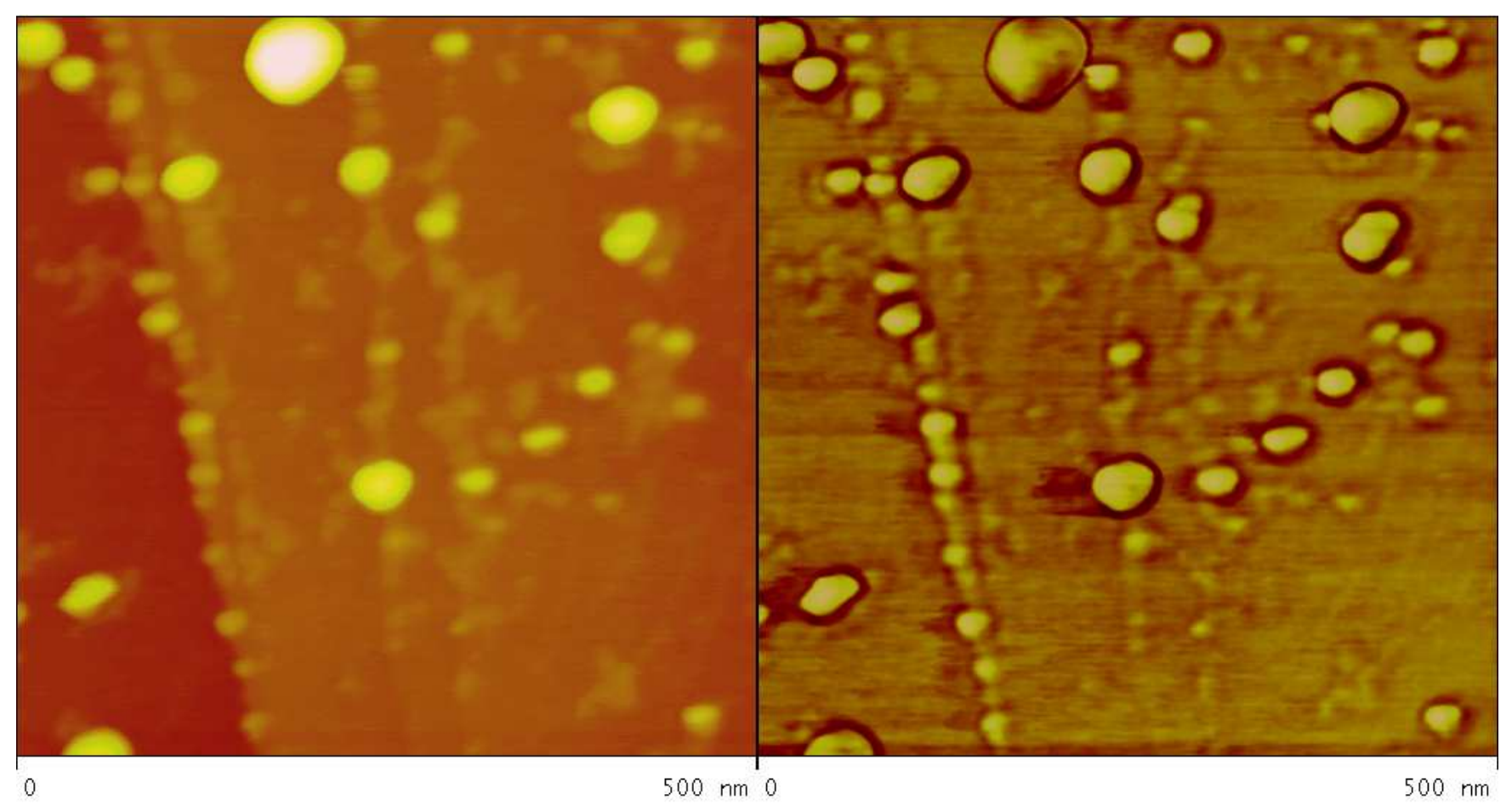

